\title{
Unusual Giant Syringomyelia with Neurocutaneous Melanosis
}

\author{
Shrestha $\mathbf{R}^{1}$, Cohen $\mathrm{AR}^{2}$
}

\section{Introduction}

A two year old male presented with feeding intolerance and Alethargy. Mother had normal delivery with term baby. The patient denied previous trauma or recent weight loss. Physical examination revealed neurocutaneous melanosis (NCM) over lower back side of body and no signs of peripheral motor deficit or abnormal reflexes. Hematological investigations showed no abnormality. Magnetic resonance (MR) imaging found a large, cystic cavity that was eccentric in the cervicothoracic spine extending from C3 to L1. Suboccipital decompressive craniectomy, bilateral C1 laminectomy, and occipital duraplasty were done.

\section{Discussion}

A NCM and syringomyelia were outlined by Rokitansky and Estienne in 1861 and 1824 respectively. NCM is a rare congenital neurocutanous disorder associated with single or numerous pigmented cutaneous nevi on the skin and involvement of the leptomeninges of the central nervous system. Syringomyelia is
'Dr. Rajendra Shrestha MD, Fellow in paediatric Neurosurgery, ${ }^{2} \mathrm{Dr}$. Alan R Cohen MD Both from the Department of Neurosurgery, Harvard Medical School/Boston Children Hospital, 300 Longwood Avenue, Boston, MA 02115, USA

\section{Address for correspondence: \\ Dr. Rajendra Shrestha \\ E-mail: rajendra.shrestha@childrens.harvard.edu}

\section{How to cite}

Shrestha R, Cohen AR. Unusual Giant Syringomyelia with Neurocutaneous Melanosis. J Nepal Paediatr Soc 2014;34(3):250-251.

doi: http://dx.doi.org/10.3126/jnps.v34i3.11165

This work is licensed under a Creative Commons Attribution 3.0 License.

\section{(c) (i)}

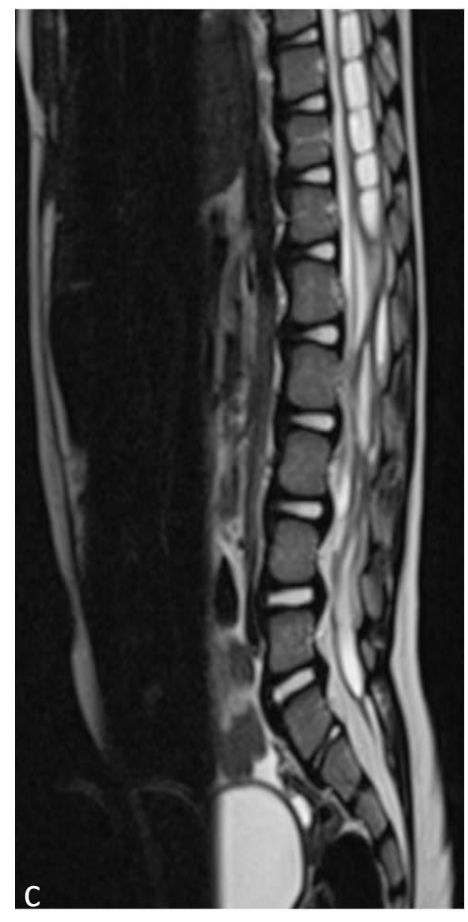

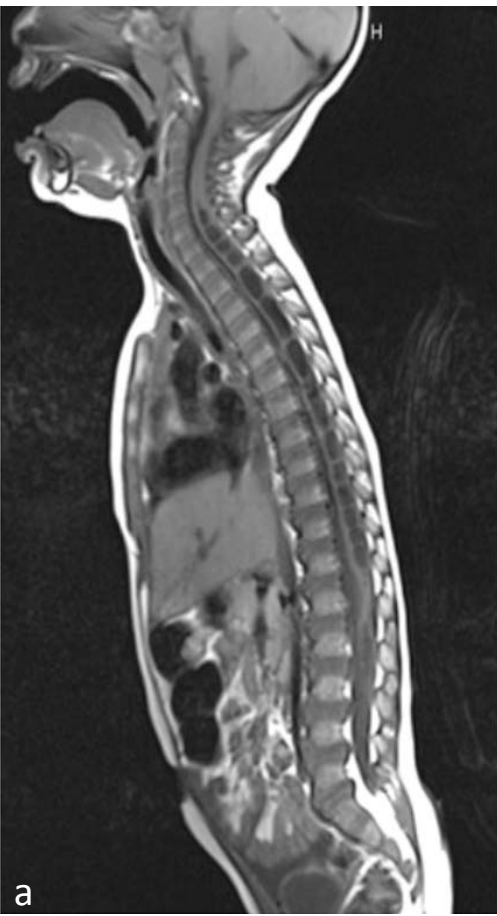

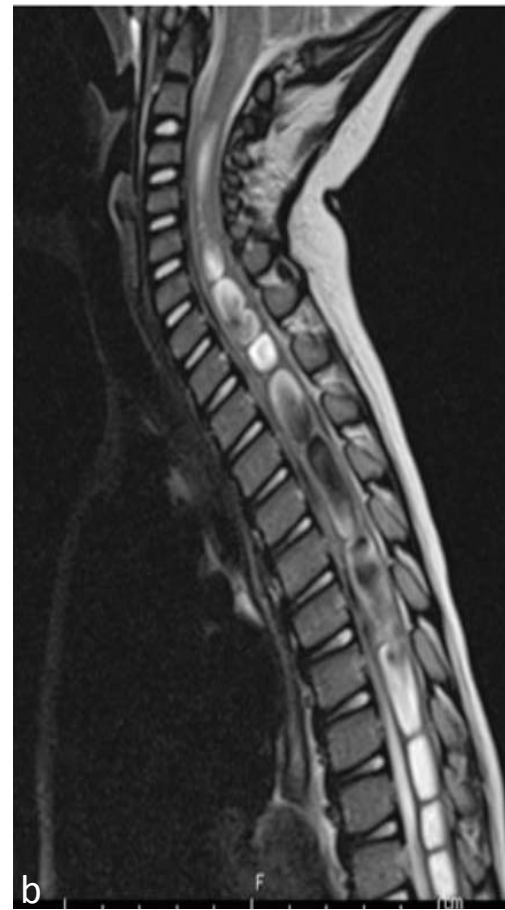

Fig 1: a) Sagittal T1 spine, b) Sagittal T2 weighted cervicothoracic spine and c) Sagittal T2 thoracic and lumbosacral spine MRI showing the syringomyelia extending from C3 and terminating at the T12-L1 
a fluid filled cystic cavity or syrinx within the spinal cord that is associated with a Chiari type 1 but our case associated with $\mathrm{NCM}^{1,2}$. It is tricky to determine whether the occurrence of this rare association (NCM and syrinx) in the same patient is just a coincidence or whether they have a common pathophysiology. Their pathology is not entirely clear till now.This suggests that the association is more a coincidence. The coexistence of these two lesions has not been documented in the literatures.

\section{References}

1. Batzdorf U: A Brief History of Syringomyelia in Syringomyelia: Current Concepts in Pathogenesis and Management. N.Tamaki, U.Batzdorf, T. Nagashima, eds.2001. Springer Verlag

2. Kadonaga J, Frieden I. Neurocutaneous melanosis. Definition and review of the literature. J Am Acad Dermatol 1991;24:747-55. 